\title{
A ESCRITA A PARTIR DA PEDRA
}

\author{
Rodrigo José Brasil Silva \\ UFSC / CAPES
}

RESUMO: 0 artigo destaca a importância da imagem da pedra para a poesia de Carlos Drummond de Andrade e procura analisar algumas questões que esse elemento do poema "No meio do caminho" evoca ao longo de toda a sua obra. Entre elas, a relação do poeta com a sociedade, a crise da representação, as fissuras da linguagem poética. 0 texto faz uma breve revisão da recepção críitca recebida pelo poema citado, um dos mais comentados de nossa literatura. Mostra ainda como a preocupação com a questão da representação e a problematização em torno da linguagem trouxeram densidade à sua poesia reflexiva, ao mesmo tempo em que lhe permitiram situar-se em seu contexto histórico e social.

PALAVRAS-CHAVE: Carlos Drummond de Andrade; Crise da representação; Linguagem poética.

\section{THE WRITING FROM THE STONE}

ABSTRACT: The article highlights the importance of the image of the stone for the poetry of Carlos Drummond de Andrade and aims to analyze some questions that this element of the poem "In the middle of the path" evokes throughout his work. Among them, the relation of the poet to the society, the crisis of the representation, the fissures of the poetic language. The text briefly reviews the critical reception received by the mentioned poem, one of the most commented in our literature. It also shows how the preoccupation with the question of representation and the discussion around the language have brought density to its reflective poetry, at the same time that allowed him to tune his poetry within his historical and social context.

KEYWORDS: Carlos Drummond de Andrade; Crisis of representation; Poetic language.

Rodrigo José Brasil Silva é doutorando do Programa de Pós-Graduação em Literatura na Universidade Federal de Santa Catarina. 


\title{
A ESCRITA A PARTIR DA PEDRA
}

\author{
Rodrigo José Brasil Silva
}

No meio do caminho tinha uma pedra. Tinha uma pedra no meio do caminho. Mas isso nunca foi obstáculo para Carlos Drummond de Andrade escrever sua poesia. Pelo contrário, podemos mesmo pensar que a consciência crítica do poeta sobre as dificuldades e vicissitudes da condição humana e da criação artística foi a pedra fundamental que lhe permitiu, desde o seu primeiro livro, Alguma Poesia, publicado em 1930, escrever com agudeza e radicalidade, em consonância com os paradigmas da modernidade.

Antonio Candido identifica uma inquietude constante na poesia de Drummond, "[...] em que a força dos problemas é tão intensa que o poema parece crescer e organizar-se em torno deles, como arquitetura que os projeta." ${ }^{1}$ Segundo o crítico, a subjetividade do poeta se apresenta de modo sempre problemático, seja devido ao seu desconforto com relação ao próprio eu retorcido, à incapacidade de aderir à vida ou à dificuldade de se situar num mundo caduco.

Em sua dureza de pedra, Drummond parece considerar o obstáculo e a inadequação como características da própria condição humana. O obstáculo e o desencontro caracterizam uma espécie de mundo avesso, onde os atos não têm sentido e os arroubos sentimentais são motivos de escárnio e ironia. O poeta é vítima de uma subjetividade tirânica e patética, que o leva ao remorso, a querer escapar do eu e da subjetividade.

A incapacidade de aderir à vida e a desconfiança em relação ao mundo levam o poeta a um movimento de volta sobre si mesmo e despertam uma desconfiança em sua relação com o mundo, consigo mesmo e sua obra poética. A consciência crispada revela um constrangimento da personalidade e - leva a investigar a máquina retorcida da alma; mas também a considerar a sua relação com o outro, no amor, na família, na sociedade. Ele se torna assim dono de sua própria livre expressão, livre dos condicionamentos da sociedade.

Drummond fez da impossibilidade de ser espontâneo e confortável em seu próprio eu lírico o caminho dificultoso da procura da poesia a partir da reflexão e da reinvenção da linguagem cotidiana. Em entrevista a Pedro Bloch,

${ }^{1}$ CANDIDO, Antonio. Vários escritos. São Paulo: Duas Cidades, 1995, p. 111-145. 
de 1963 , o poeta mineiro afirmou que a poesia, para ele, resulta "da inconformidade com o mundo" 2 . Criar, portanto, implica uma dificuldade, um caminho pedregoso, e não um ato espontâneo e natural. Escrever para ele nunca era fácil - a pedra estava sempre presente. "Nunca me esquecerei desse acontecimento/ na vida de minhas retinas tão fatigadas."

De acordo com Davi Arrigucci Jr., a pedra será, recorrentemente, a pedra no caminho de toda criação drummondiana. A pedra é, simultaneamente, o fator desencadeante e o entrave do ato poético, que move o poeta à reflexão e à procura incessante da poesia, obrigando-o a permanecer no círculo infernal da busca sem fim." ${ }^{3}$

Escrito em fins de 1924 ou no início de 1925, "No meio do caminho" foi publicado pela primeira vez na Revista de Antropofagia, em 1928, e depois incluído no livro Alguma poesia. O poema ganhou bastante repercussão na década de 30 , por sua forma ousada e iconoclasta, tão diferente da concepção predominante sobre o que se considerava a poesia até então. A pedra aproxima a poesia do prosaico, do cotidiano, propondo uma poesia com os pés no chão, em contraponto aos altos voos dos poetas parnasianos e condoreiros. Nas palavras de Davi Arrigucci Jr.:

\begin{abstract}
O emprego do verbo ter, em vez de haver, no primeiro verso, até hoje assusta os puristas; o espaço nobre da poesia escrita vinha tomado pela fala coloquial; os mesmos segmentos de verso se repetiam mecanicamente quase no poema todo, pregando uma peça permutante, absurdamente antipoética segundo os padrões habituais, que fugiam da redundância; por fim, a completa banalidade do que ali se considera literalmente um acontecimento, isto é, topar com uma pedra no caminho. ${ }^{4}$
\end{abstract}

A princípio, a pedra no caminho foi associada ao humor e ao chiste, à rebeldia, ao gosto pela novidade, à oposição ao passado, que marcaram os primeiros anos da militância modernista. Mas Drummond também estava falando sério, mesmo quando brincava. Conforme observa Arrigucci, "tudo nele tende a adquirir a densidade de um mundo interior sério e problemático, provocando o desconcerto, em contraste com a face álacre da comicidade". Nas palavras de Drummond: "O homem atrás do bigode / é sério, simples e forte." 5

2 ANDRADE, Carlos Drummond de. Entrevista a Pedro Bloch. Revista Manchete, n. 582, 15 jun. 1963.

3 ARRIGUCCI Jr, Davi. Coração Partido. Uma análise da poesia reflexiva de Drummond. São Paulo: Cosac Naify, 2002, p. 72-73.

4 Ibidem, p. 70.

5 ANDRADE, Carlos Drummond de. Alguma Poesia. In: Nova Reunião. Rio de Janeiro: Livraria José Olympio Editora, 1983, p. 3. 
O poema se tornou mesmo uma pedra no sapato dos críticos, que se desdobram para desvendar o seu "mistério". Porém, a pedra oferece possibilidades de interpretação diferentes para cada leitor que se deparar com ela. Imersa no poema, num estado de dicionário, para cada qual ela perguntará: trouxeste a chave?

\section{A CRISE DA REPRESENTAÇÃO}

Drummond tinha consciência de que nossa relação com o mundo é mediada pela subjetividade e pela estrutura simbólica da linguagem. A poesia, afinal, é feita de palavras, que são capazes de representar as coisas, mas não de ser a própria coisa. A pedra, no final das contas, é apenas uma palavra que representa uma pedra. A barreira estaria, nessa perspectiva, no meio do caminho entre as palavras e as coisas.

Esse percurso entre a subjetividade e a realidade objetiva que nos cerca se tornou ainda mais problemático na modernidade, em que se instaurou a chamada "crise da representação", problematização em torno do vínculo entre os signos e a realidade, a palavra e as coisas, o significante e o significado. Podese pensar que essa desconfiança crítica, que remonta ao século XIX, está na origem do caráter moderno da arte. A partir de então, as palavras se tornaram símbolos ambíguos e pouco confiáveis. "Vivemos dentro da linguagem como aspiramos o ar poluído", observa Guy-Ernst Debord. ${ }^{6}$

Segundo Franklin Leopoldo Silva, a crise da representação marca o fim de uma transição tranquila entre as coisas e as palavras. ${ }^{7}$ Ela obriga o poeta a aceitar a ambiguidade, a ambivalência e o desvio como fatores que são parte integrante da poesia. A palavra poética será, neste contexto, sempre ambígua e desviante, porque as referências se mostram fugidias e polivalentes. Resta ao poeta uma expressão das metades, das cisões, daquilo que está relacionado por oposição e não por complementariedade.

Podemos pensar que a consciência crítica caracteriza a poesia moderna. Embora seja muito difícil definir o que "moderno" significa, talvez possamos caracterizá-lo pela presença no poema de um sentimento de aspereza, complexidade problemática, o estranhamento entre o poeta e o público. ${ }^{8}$

Na segunda metade do século XIX, a noção de que existe um mundo objetivo a ser desvendado pela razão começou a sofrer abalos. Pensadores como

${ }^{6}$ DEBORD, Guy-Ernst. Todos os homens do rei. Coyote, n. 4, 2003, p. 38-39, 2003.

7 SILVA, Franklin Leopoldo. Curso de Filosofia e Intuição Poética na Modernidade. USP / Univesp, 2013.

8 FRASER, George Sutherland. The modern writer and his world. London: Penguin, 1968, s/n. 
Freud, Nietzsche e Marx, os chamados "mestres da suspeita" ${ }^{9}$, chamaram a atenção para as ilusões da consciência e intensificaram as críticas ao conceito de verdade como representação e correspondência. A ausência do ideal, a perda da noção de totalidade, a impossibilidade de harmonia e a diluição da comunidade de sentido representam dificuldades intrínsecas e imponderáveis, levando à fragmentação e ao dilaceramento do indivíduo. Os valores que o sustentavam - religião, pátria, família, a própria razão - sofreram abalos avassaladores com as guerras mundiais, a eugenia, a crise econômica mundial de 1929. A incapacidade de aderir à vida e a desconfiança em relação ao mundo levam o poeta a um movimento de volta sobre si mesmo e despertam desconfiança em sua relação com o mundo, consigo mesmo e sua obra poética.

\section{UM MOMENTO DE SUSPENSÃO}

A pedra é um obstáculo que leva o poeta a se debruçar sobre a própria escrita. Segundo Antonio Candido, o discurso poético é aquele que chama a atenção sobre si mesmo e implica um atenuante em sua relação com o referencial. O obstáculo no meio do caminho possibilita ao poeta ver o mundo com um distanciamento analítico e crítico e desconstruir aquilo que está naturalizado na vida e na literatura. Ele propicia um distanciamento, um momento de suspensão e um intervalo para reflexão que permitem ao escritor lançar um olhar crítico sobre a linguagem convencional, de modo a desconstrui-la, subvertê-la e reinventá-la. Nas palavras do critico:

As palavras parecem entidades rebeldes e múltiplas, que o poeta procura atrair, mas que fogem sempre, quer ele as acaricie, quer as maltrate. É uma luta desigual e inglória, contra objetos imponderáveis que se desfazem ao contato, mas que fascinam, e aos quais o poeta não consegue renunciar.

A pedra no caminho faz com que o poeta possa se debruçar sobre a linguagem e exercer um antagonismo em relação ao prosaísmo alienante da linguagem instrumental, que se apresenta como barreira à expressão poética, buscando alcançar na própria linguagem o caminho que ela gostaria de seguir, conforme sugere Adorno. ${ }^{10}$ As palavras são justapostas no poema seguindo critérios não de complementaridade ou linearidade, mas de contraposição e independência, explorando as possibilidades sintáticas. Ao colocar em evidência o "lado palpável" do signo linguístico e a sua função poética, a poesia apro-

${ }^{9}$ A expressão foi cunhada pelo filósofo francês Paul Ricoeur.

${ }^{10}$ ADORNO, Theodor W. Notas de Literatura 1. Palestra sobre lírica e sociedade. São Paulo: Editora 34,2003, p. 74. 
funda a dicotomia fundamental entre os signos e os objetos, lembrando que linguagem é linguagem, e não a verdade material das coisas. ${ }^{11}$

Essa valorização da função poética, porém, não implica num esvaziamento do significado ou da analogia com a realidade nem oblitera a referência (a denotação), mas torna-a ambígua. No limite, ele tanto chama a atenção sobre si que faz esquecer o mundo, tornando-se outro mundo e abrindo caminho para outros significados latentes. ${ }^{12}$

Ao alcançar o estado de poesia, a palavra se desvia da referencialidade em relação às coisas e desperta de seu estado de dicionário para se tornar uma coisa nova, ainda em relação com o mundo, mas não submetido a ele. Ela não se limita a representar o mundo, mas inaugura seu próprio mundo, ao mesmo tempo em que mantém uma relação com o mundo, reinventando-o. A poesia se revela, portanto, uma força capaz de ampliar nosso campo de conhecimento e subverter a razão justamente nos limites que ela impõe a si mesma. Porém, se a razão pode nos levar à loucura, à guerra, ao paroxismo da própria razão, o que haverá para além da razão? Talvez a poesia. Nas palavras de Walter Benjamin:

\begin{abstract}
Aparentemente insignificante e ridículo diante da barreira que o oprime, mostra-se eficaz e adquire significação social, apesar de seu isolamento, pois é capaz de produzir mudança mesmo em face do maior bloqueio. Ainda que mínimo, o ato poético participa na criação do destino humano, faz história. Para tanto, ele deve ser fiel, contra toda a dificuldade, à sua própria natureza de poder ser, pois cria assim uma imagem nova - o poema, abrindo uma possibilidade inscrita em sua forma: a saída para o sentido. ${ }^{13}$
\end{abstract}

Quando pensamos a pedra como obstáculo, estamos ainda vendo a pedra na perspectiva do poeta Drummond, e não como a coisa em si. Mas o que causa uma sensação de estranheza na leitura desse poema é que a pedra parece falar por si mesma, e não ser um símbolo ou uma imagem para o poeta dizer alguma coisa utilizando a linguagem instrumental. A pedra causa uma fissura na linguagem e abre o caminho para novos sentidos. A expressão se torna ela própria uma espécie de objeto, propiciando uma espécie de catarse ou epifania - do material e do mundano, e não do sublime.

\footnotetext{
${ }^{11}$ JAKOBSON, Roman. Linguística e comunicação. Trad. Izidoro Blikstein e José Paulo Paes. São Paulo: Cultrix, 1970, p. 128.

12 CANDIDO, Antonio. O mundo desfeito e refeito. In: Recortes. São Paulo: Companhia das Letras, 1993, p. 32.

13 BENJAMIN, Walter. Magia e técnica, arte e política. In: Obras escolhidas. 7 a edição. Tradução de Sergio Paulo Rouanet. São Paulo: Brasiliense, 1994, p. 22.
} 
Essa pedra, tão familiar e cotidiana, de repente nos revela sua face e nos causa vertigem e estranheza, pois objetos inanimados não deveriam ter vida própria, o que nos remete ao texto "O Estranho", de Freud. ${ }^{14}$ Sim, a pedra também nos olha. Ela então nos lembra daqueles tempos idílicos em que a consciência dos homens não estava separada do mundo e das coisas. Assim, a poesia elide sujeito e objeto.

A pedra nos lembra de que a poesia é feita de palavras, não de pensamentos. E assim as palavras se tornam as coisas, em vez de expressarem as coisas. E ao romper o seu silêncio de pedra, a palavra pode falar por si própria, a partir das imagens. Quem fala é a pedra, e não o poeta. A imagem da pedra. No meio do caminho.

${ }^{14}$ FREUD, Sigmund. O estranho. In: Obras completas. Edição Standard Brasileira V. XVII. Rio de Janeiro: Imago, 1986. 